\title{
Major Limb Amputation Secondary to Locally Advanced Cutaneous Squamous Cell Carcinoma in Tropical Environments: Determinants
}

\author{
Kouassi Kouamé Jean Eric, Yao Loukou Blaise, Sery Bada Justin Leopold Niaoré, \\ M'bra Kouamé Innocent, Krah Koffi Léopold, Kouassi Aya Adelaide Nathacha, \\ Assere Yao Aboh Ganyn Robert Arnaud, Kodo Michel
}

Trauma and Orthopedics Department, Bouake Teaching Hospital, Bouake, Ivory Coast

Email: medericko@yahoo.fr

How to cite this paper: Eric, K.K.J., Blaise, Y.L.., Niaoré, S.B.J.L., Innocent, M.K., Léopold, K.K., Nathacha, K.A.A., Arnaud, A.Y.A.G.R. and Michel, K. (2018) Major Limb Amputation Secondary to Locally Advanced Cutaneous Squamous Cell Carcinoma in Tropical Environments: Determinants. Open Journal of Orthopedics, 8 , 139-147.

https://doi.org/10.4236/ojo.2018.84017

Received: February 21, 2018

Accepted: April 10, 2018

Published: April 13, 2018

Copyright $\odot 2018$ by authors and Scientific Research Publishing Inc. This work is licensed under the Creative Commons Attribution International License (CC BY 4.0).

http://creativecommons.org/licenses/by/4.0/ (C) (i) Open Access

\begin{abstract}
Objective: To identify the determinants of secondary limb amputation in advanced squamous cell carcinoma. Material and Methods: This was a retrospective study carried out in the Orthopedic Traumatology Department of the Bouaké University Hospital in Côte d'Ivoire from January 2013 to December 2016. It involved ten patients with locally advanced skin squamous cell carcinoma, confirmed by histology and having amputated limbs. The parameters studied were: demographic data (gender, age), socio-economic conditions (occupation, place of residence), the risk factors involved, the use of topical self-medication and the use of traditional medicine, antecedents and comorbidities factors, lifestyle, clinical aspects (seat, size), extension assessment (X-ray), anatomo-pathological examination data, duration of evolution of squamous cell carcinoma, the function of the affected limb, the treatment performed, the evolutionary modalities and the equipment. Results: Between 2013 and 2016, ten patients underwent either upper or lower limb amputations following locally advanced squamous cell carcinoma. The average age was 34.1 years (19 - 64 years). There were 7 men (70\%) and 3 women (30\%) and all our patients were black (sub-Saharan Africa). The majority of our patients were farmers (70\%). The risk factors for squamous cell carcinoma were neglected chronic wounds. All our patients recognized during the interrogation a large use of the topicals of traditional medicine for the treatment of the initial cutaneous lesions. In terms of lifestyle, five (50\%) were smokers and alcoholics. The mean time to progression of squamous cell carcinoma was 5.9 years. Lesions were localized preferentially to the pelvic limbs six (60\%) cases and four (40\%) to the limbs chest. The lesion was diagnosed late in all our patients. The size of the tumor in all our patients was greater than $5 \mathrm{~cm}$ and had a deep invasion (nerves, vessels and bone). The proximal ipsilateral ganglionic
\end{abstract}


invasion was constant. The extension assessment (chest X-ray) showed two cases of pulmonary metastases. Seven patients (70\%) had well-differentiated tumors. All patients underwent amputation of the affected limb, sometimes coupled with an accessible lymph node dissection. The evolution was favorable (no recurrence and infection of the amputation stump). The function of the affected limb was limited in all our patients. Seven patients (70\%) survive, three of whom have been fitted to the lower limb and are regularly followed on an outpatient basis. We noted three (30\%) deaths after the surgical treatment. Conclusion: Limb amputation in patients with locally advanced skin squamous cell carcinoma may be associated with cancer aggressiveness, the socio-economic conditions of patients, the quality of care, and the patient's relationship to the disease.

\section{Keywords}

Amputation, Squamous Cell Carcinoma, Cutaneous, Histology

\section{Introduction}

Cutaneous carcinomas are the most common skin cancers in the world, both on black skin and on white skin. But unlike white skin, their prevalence is low in black [1] [2] [3]. In addition, black skin has a large predominance of squamous cell carcinoma (EC) (or "squamous cell carcinoma") compared with basal cell carcinoma (BCC) [4]. Cutaneous squamous cell carcinoma (SCC) is a malignant tumor developed from epidermal keratinocytes [5]. They represent a real public health problem because of their morbidity and mortality. Its chronic evolution is marked by a progressive extension of the tumor to the skin and to the underlying tissues, then the appearance of lymph node metastases [6]. The prognosis of cutaneous squamous cell carcinoma seems to correlate well with the size of the tumor, the location, the depth of the lesion and the degree of differentiation [7]. The curative treatment of cutaneous squamous cell carcinoma involves several therapeutic means including Exeresis which remains the best choice, because only this treatment allows a histological control of the margins of excision and therefore a better control of the evolution in the medium and long term [8]. Amputation is only used in advanced cases [9], and some associated factors such as access to public health, the quality of health care and the patient's relationship with the disease [10]. We conducted this study which aimed to identify the determinants of limb amputation, in order to contribute to prevention in our population.

\section{Material and Methods}

This was a retrospective study conducted in the Department of Orthopedic Traumatology of the University Hospital of Bouaké in Ivory Coast. She focused on the patients' records from January 2013-December 2016 for cutaneous squamous cell carcinoma. Included in our study were all patients with histologically confirmed squamous cell carcinoma (Figure 1) and had the limb amputated. 


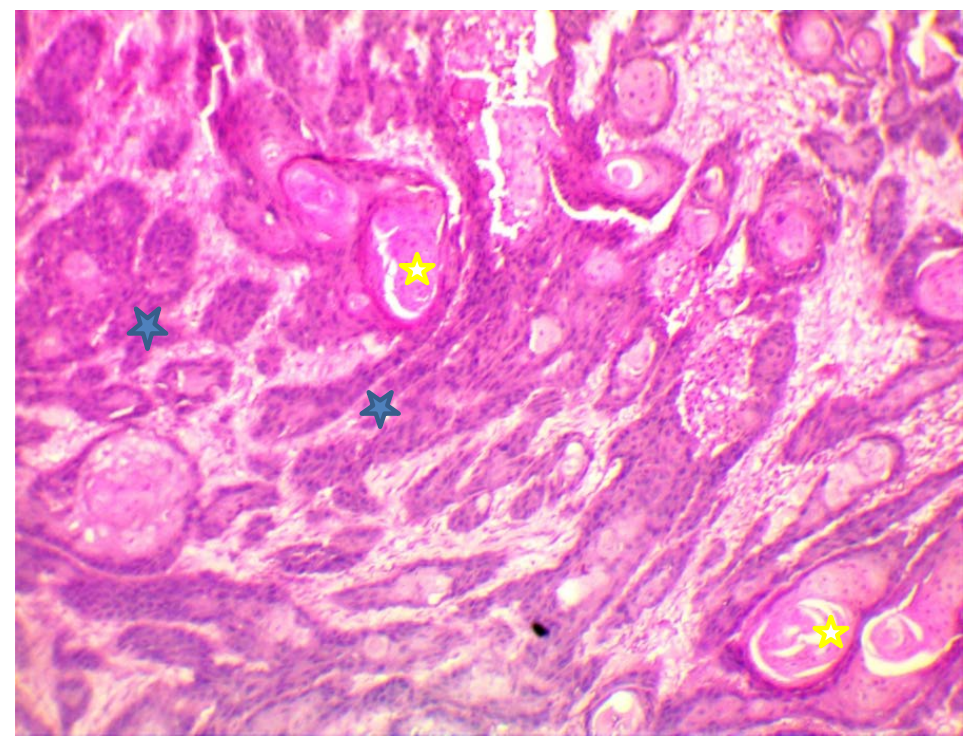

Figure 1. Histological appearance of a well-differentiated mature and infiltrating squamous cell carcinoma made of trabeculae, tumor lobules (blue star) with corneal maturation foci (yellow star).

All cases of squamous cell carcinoma of suspected limb on clinical examination not confirmed by histology were excluded. Lesions placed proximal to the buttock and groin crease or the acromion and axillary apex were excluded. Data were collected from patients' medical records. The parameters studied were: demographic data (gender, age), socio-economic conditions (occupation, place of residence), the risk factors involved, the use of topical self-medication and the use of traditional medicine, antecedents and comorbidities factors, lifestyle, clinical aspects (seat, size), extension assessment (X-ray), anatomo-pathological examination data, duration of evolution of squamous cell carcinoma, the function of the affected limb, the treatment performed, the evolutionary modalities and the equipment.

The data was recorded and analyzed with SPSS software version 24 (IBM SPSS Statistics 24.0). Qualitative variables were described with proportions and quantitative variables in terms of mean.

\section{Results}

Between 2013 and 2016, ten patients underwent either upper or lower limb amputations following locally advanced squamous cell carcinoma. The average age was 34.1 years (19 - 64 years). There were 7 men (70\%) and 3 women (30\%) and all our patients were black (sub-Saharan Africa). The majority of our patients were farmers $(70 \%)$ and $30 \%$ worked in small trades (sartorius, mechanic, trader). The risk factors for squamous cell carcinoma were neglected chronic wounds, including: four (40\%) tropical ulcers (four cases), and two (20\%) neglected trauma ulcers, two (20\%) ulcers per burn, and two (20\%) ulcers on pruriginous nodule. All our patients were immunocompetent and recognized at the time of the interrogation a large recourse to the topical of the traditional medi- 
cine for the treatment of the initial cutaneous lesions. In terms of lifestyle, five (50\%) were smokers and alcoholics, three $(30 \%)$ were smokers only and two (20\%) were alcoholics. The characteristics of the patients are grouped in Table 1.

The mean time to progression of squamous cell carcinoma was 5.9 years. The lesions were localized preferentially to the pelvic limbs six (60\%) cases and four $(40 \%)$ to the thoracic limbs. The lesion was diagnosed late in all our patients. The size of the tumor in all our patients was greater than $5 \mathrm{~cm}$ and had a deep invasion (nerves, vessels and bone). The proximal ipsilateral ganglionic invasion was constant. The extension assessment (chest X-ray) showed two cases of pulmonary metastases. Seven patients (70\%) had well differentiated tumors and two (20\%) moderately differentiated tumors. All patients underwent amputation of the affected limb coupled with lymph node dissection. The evolution was favorable in the majority of the cases. There was a recurrence of the forearm amputation stump, which required revision. The function of the affected limb was limited in all our patients. No patients did radiotherapy (not available during the study) and chemotherapy because of the expensive cost. We noted three (30\%) deaths after the surgical treatment. Including two cases of extensive tumors (wrist and knee) with pulmonary metastases and one patient who had been reoperated for recurrence of the tumor on the forearm amputation stump, who died 5 months later. Seven patients (70\%) survive, three of whom were paired with the lower limb. During the follow-up we did not notice any recurrence and the patients during the first year were reviewed twice a year, then once a year from the second year.

Table 1. Patients characteristics.

\begin{tabular}{ccc}
\hline Characteristics number of patients & $\%$ \\
\hline Gender & 7 & $70 \%$ \\
Male & 3 & $30 \%$ \\
Female & & \\
Way of life & 8 & $80 \%$ \\
Alcohol + tobacco & 2 & $20 \%$ \\
Alcohol & & \\
Seat & 4 & $40 \%$ \\
Upper limb & 6 & $60 \%$ \\
Lower limb & & \\
Tumor size & 2 & $20 \%$ \\
$5-10 \mathrm{~cm}$ & 7 & $70 \%$ \\
$10-20 \mathrm{~cm}$ & 1 & $10 \%$ \\
$>20 \mathrm{~cm}$ & & \\
Histological type & 7 & $70 \%$ \\
Well differentiated & 2 & $10 \%$ \\
Moderately differentiated & 1 & \\
Little differentiated & &
\end{tabular}




\section{Discussion}

Cancers are distributed very differently according to populations and geographical areas. Among the identified determinants of this variability are exposure to oncogenic viruses or environmental carcinogens, particular genetic susceptibility, behavioral or social factors [6].

The occurrence of skin cancers is mainly a function of the phototype of the exposed subject. Cutaneous squamous cell carcinoma (SCC) is a malignant tumor with low aggressiveness and moderate metastatic potential [9] [11] [12] [13] [14], which can be cured when treatment is early [11] [14] [15]. Even with the late diagnosis of more advanced lesions, there is always a chance of healing, which, however, requires extensive resections, with higher functional sequelae [10].

Prognostic factors for squamous cell carcinoma include anatomical site, size, tumor thickness, level of invasion, rate of growth, etiology, degree of histological differentiation, and host immunosuppression [16]. Some factors predict a poor prognosis. These include SCC recurrent, size $>4 \mathrm{~cm}$, deep invasion $(>7 \mathrm{~mm})$, perineural invasion, extracapsular extension of lymph node metastases, more than one lymph node positive for metastases, and the immunocompromised state [17].

In our study all tumors were large at the time of diagnosis of malignancy ( $>5$ $\mathrm{cm}$ in diameter) (Figures 2(a)-(f)), as well as data from the literature [18] [19] [20]. This could be explained by the duration of evolution of the tumor and also by the management of initial non-neoplastic skin lesions. In sub-Saharan Africa, cutaneous squamous cell carcinoma occurs almost exclusively on scar scars, dermatoses or chronic ulcers initially non-neoplastic [6]. In view of the under-medicalization, ulcers are treated during traditionally, the hospital being only the last resort. Some plants traditionally used to treat these ulcers could be aggressive and carcinogenic, and would be the cause of the early occurrence of squamous cell carcinoma [4]. The anatomical site also plays a fundamental role. The occurrence of squamous cell carcinoma on chronic inflammatory dermatoses (scar, chronic ulcer) is correlated with a very aggressive evolution with a risk of metastasis approaching 40\% [21] [22].

The lymph node metastasis, pulmonary bone, liver are indeed noted from the outset in $1 / 3$ of cases in most series, or occur for $2 / 3$ of them in the year following the diagnosis, two elements that invite not to postpone the surgical decision [6]. In our study squamous cell carcinoma occurred on neglected chronic ulcers with nodal involvement that was constant in all patients with pulmonary localization in two patients. It seems that the poor prognosis of such tumors is related to the usual diagnostic delay, the poor immune response and also to the poor local vascularization which certainly plays a role [21] [22]. The degree of differentiation in our study was dominated by well-differentiated tumors (70\%) followed by moderately differentiated (20\%). This is found in the literature [23]. Cutaneous squamous cell carcinoma with little or no differentiation has a risk of 


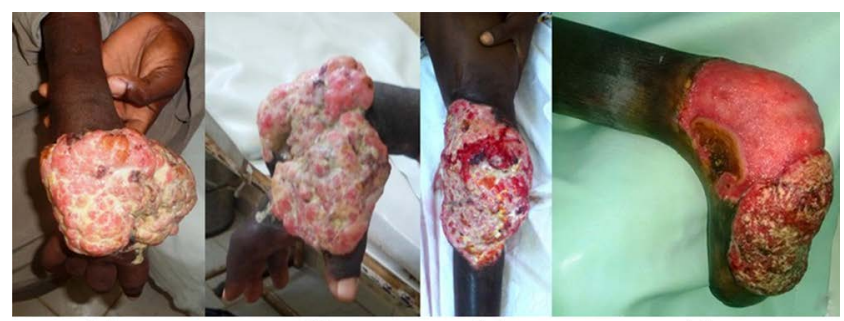

(a)

(b)

(c)

(d)

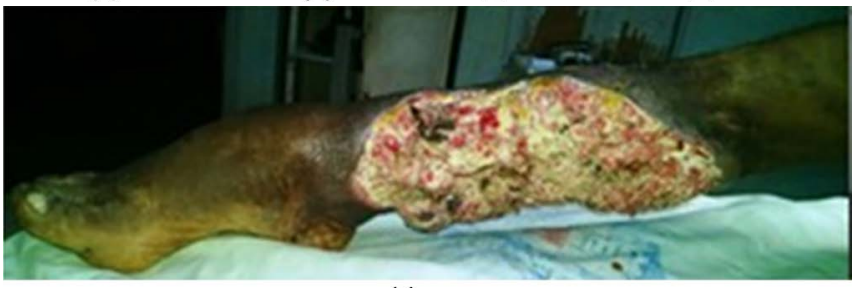

(e)

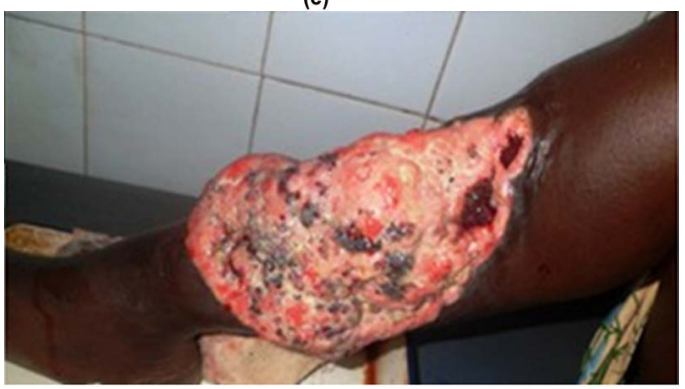

(f)

Figure 2. Showing the different localization of locally advanced squamous cell carcinoma.

double local recurrence and a risk of triple metastasis compared with well-differentiated tumors [8] [9] [11].

All our patients had a prognosis aggravated by problems related to limited resources or access to the specialized health center. It was also noted that none of the patients who had an amputation had a level of education such as a primary, secondary or higher education diploma, which makes it difficult to understand the severity of the disease and the importance of early treatment [10].

All patients had known chronic risk factors for chronic neglected skin ulcers and were mostly smokers. The role of tobacco is reported in the induction of cutaneous cancer lesion. In fact, while tobacco smoke is carcinogenic by the polycyclic aromatic hydrocarbons it contains, uncontaminated tobacco is also carcinogenic because it contains nitrosamines, which can act both at initiation and conversion. Smokeless smoking is therefore likely to cause cutaneous squamous cell carcinoma [24].

The average time between the onset of the lesion and the definitive diagnosis (histopathological) was relatively long, nearly 6 years. All our patients had locally advanced lesions affecting bones, joints (Figure 3), vessels, and nerves (stage T4) [14], with partial loss of function of affected limbs. Patients with advanced lesions (>T2) have a high risk of locoregional and metastatic spread [11] [14], highlighting the importance of early diagnosis and appropriate surgical approach, avoiding results such as amputation or death in patients with locally 


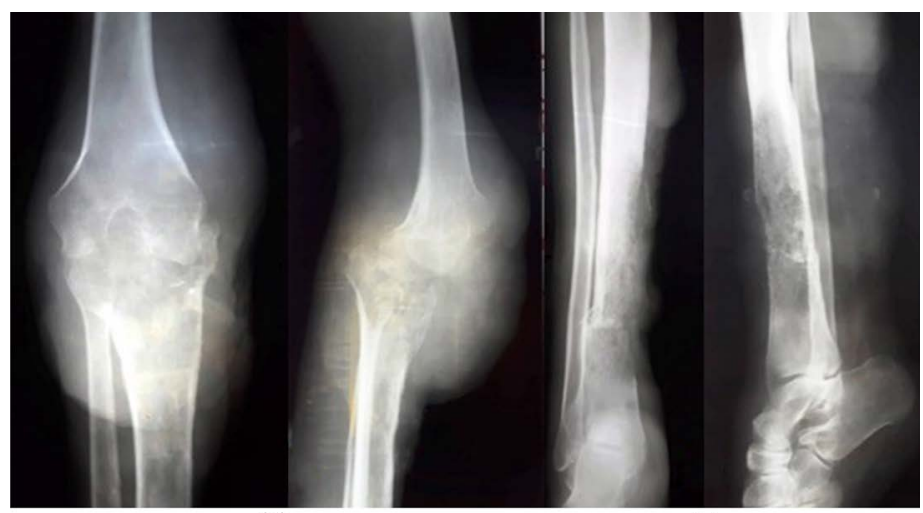

(a)

(b)

Figure 3. Joint (a) and Bone (b) involvement contiguous to locally advanced squamous cell carcinoma.

indolent behavioral disease in most cases [10].

Treatment is based on surgical excision [8]. When the disease is correctly diagnosed at an early stage, resection or cauterization is possible and can be performed by a general practitioner, a dermatologist or a surgeon, with a good prognosis for the patient [10]. However, amputation is proposed as a palliative treatment for locally advanced squamous cell carcinoma [17] [25], as is the case in all our patients.

When the indication is put, it is necessary to discuss the level with the patient and his entourage, because the amputation remains a particularly dramatic gesture in Africa, because it makes patients marginalized of the society.

Since our study was conducted in a small number of cases, further work and analysis are needed to establish statistical correlations and quantify the impact of these factors in patients with advanced skin cancer.

\section{Conclusion}

Amputation in patients with locally advanced cutaneous squamous cell carcinoma, in addition to being associated with aggressive cancer and comorbidities may be influenced by other factors such as socio-economic status, quality of care and the patient's relationship with the disease.

\section{Conflict of Interest}

The authors state that there is no conflict of interest. The patient was informed and gave contentment for this article.

\section{Author's Contribution}

All the authors contributed to the writing of this manuscript, and had read and approved the final version.

\section{References}

[1] Marks, R. (1996) Squamous Cell Carcinoma. Lancet, 347, 735-738. 
https://doi.org/10.1016/S0140-6736(96)90081-1

[2] Halder, R.M. and Bridgeman-Shah, S. (1995) Skin Cancer in African-American. Cancer, 75, 667-673.

https://doi.org/10.1002/1097-0142(19950115)75:2+<667::AID-CNCR2820751409>3. $0 . \mathrm{CO} ; 2-\mathrm{I}$

[3] Napo-Koura, G., Pitche, P., Tchangai-Walla, K., James, K. and Kpodzro, K. (1997) Skin Cancer in Togo. Bulletin du Cancer, 84, 877-879.

[4] Pitche, P. and Tchangai-Walla, K. (2006) Cancers cutanés sur peau noire. Annales De Dermatologie Et De Venereologie, 133, 932-935. https://doi.org/10.1016/S0151-9638(06)71072-9

[5] Dieng, M.T., Diop, N.N., Deme, A., Sy, T.N., Niang, S.O. and N'diaye, B. (2004) Carcinome épidermoide sur peau noire: 80 cas. Annales De Dermatologie Et De Venereologie, 131, 1055-1057. https://doi.org/10.1016/S0151-9638(04)93840-9

[6] Muller, P., Roul, S., Mahe, A., Roudier, M., Vaque, D. and Strobel, M. (2004) Carcinome épidermoïde sur ulcère de jambe aux Antilles. Annales De Dermatologie Et De Venereologie, 131, 347-350. https://doi.org/10.1016/S0151-9638(04)93613-7

[7] BonerandiJ, J. and Monestier, S. (2011) Carcinome épidermoïde (spinocellulaire) et ses précurseurs. EMC Elsevier Masson SAS, Paris, Dermatologie, 98-625-A-10.

[8] Breuninger, H., Black, B. and Rassner, G. (1990) Microstaging of Squamous Cell Carcinomas. American Journal of Clinical Pathology, 94, 624-627.

https://doi.org/10.1093/ajcp/94.5.624

[9] Rowe, D.E., Carroll, R.J. and Day Jr., C.L. (1992) Prognostic Factors for Local Recurrence, Metastasis, and Survival Rates in Squamous Cell Carcinoma of the Skin, Ear, and Lips. Implications for Treatment Modality Selection. Journal of the American Academy of Dermatology, 26, 976-990. https://doi.org/10.1016/0190-9622(92)70144-5

[10] Wainstein, A.J.A., Oliveira, T.A., Guelfi, D.C.F., Gontijo, B.R., Castro, E.V., Carvalho, R.A., Paz, N.M. and Lacerda, L.T. (2012) Limb Amputation for Squamous Cell Carcinoma of the Skin-Factors Involved in This Poor Evolution. Revista do Colégio Brasileiro de Cirurgióes, 39, 173-177. https://doi.org/10.1590/S0100-69912012000300002

[11] Cherpelis, B.S., Marcusen, C. and Lang, P.G. (2002) Prognostic Factors for Metastasis in Squamous Cell Carcinoma of the Skin. Dermatologic Surgery, 28, 268-73.

[12] Barksdale, S.K., O'Connor, N. and Barnhill, R. (1997) Prognostic Factors for Cutaneous Squamous Cell and Basal Cell Carcinoma. Determinants of Risk or Recurrence, Metastasis, and Development of Subsequent Skin Cancers. Surgical Oncology Clinics of North America, 6, 625-638.

[13] Boukamp, P. (2005) Non-Melanoma Skin Cancer: What Drives Tumor Development and Progression? Carcinogenesis, 26, 1657-1667.

https://doi.org/10.1093/carcin/bgi123

[14] Brantsch, K.D., Meisner, C., Schönfisch, B., Trilling, B., Wehner-Caroli, J., Röcken, M., et al. (2008) Analysis of Risk Factors Determining Prognosis of Cutaneus Squamous-Cell Carcinoma: A Prospective Study. The Lancet Oncology, 9, 713-720. https://doi.org/10.1016/S1470-2045(08)70178-5

[15] Weinberg, A.S., Ogle, C.A. and Shim, E.K. (2007) Metastatic Cutaneous Squamous Cell Carcinoma: An Update. Dermatologic Surgery, 33, 885-899.

[16] Pai, V.D., Pai, S.V., Manohar, V., Ravindranath, S. and Math, M.K. (2016) Primary Cutaneous Squamous Cell Carcinoma of Thigh: A Case Report and Review of Lite- 
rature. Journal of Orthopedic Oncology, 2, 106.

https://doi.org/10.4172/2472-016X.1000106

[17] Johnston, E.A., Namm, J.P. and Reeves, M.E. (2006) Case Report: Major Extremity Amputation for Nodal Metastasis from Squamous Cell Carcinoma. Journal of Surgical Oncology, 93, 76-79. https://doi.org/10.1002/jso.20347

[18] Ames, F.C. and Hickey, R.C. (1980) Squamous Cell Carcinoma of the Skin of the Extremities. International Advances in Surgical Oncology, 3, 179-199.

[19] De Asis, C. (1926) Cutaneous Carcinoma of the Lower Extremities. Annals of Surgery, 83, 663-681. https://doi.org/10.1097/00000658-192605000-00009

[20] Glass, R.L. and Spratt, J.S. (1964) Epidermoid Carcinoma of the Lower Extremities. Archives of Surgery, 89, 955-960.

https://doi.org/10.1001/archsurg.1964.01320060023005

[21] Bernstein, S.C., Lim, K.K., Brodland, D.G. and Heidelberg, K.A. (1996) The Many Faces of Squamous Cell Carcinoma. Dermatologic Surgery, 22, 243-254.

[22] Lohmann, C.M. and Solomon, A.R. (2001) Clinicopathologic Variants of Cutaneous Squamous Cell Carcinoma. Advances in Anatomic Pathology, 8, 27-36. https://doi.org/10.1097/00125480-200101000-00005

[23] Dormand, E.L., Ridha, H. and Vesely, M.J.J. (2010) Long-Term Outcome of Squamous Cell Carcinoma of the Upper and Lower Limbs. Journal of Plastic, Reconstructive \& Aesthetic Surgery, 63, 1705-1711. https://doi.org/10.1016/j.bjps.2009.10.003

[24] Bayle Lebey, P. and Bazex, J. (1994) Etats précancéreux cutanés et facteurs carcinogènes Nouv. Dermatology, 13, 246-249.

[25] Holcombe, C. and Hassan, S. (1991) Major Limb Amputation in Northern Nigeria. British Journal of Surgery, 78, 885-886. https://doi.org/10.1002/bjs.1800780735 